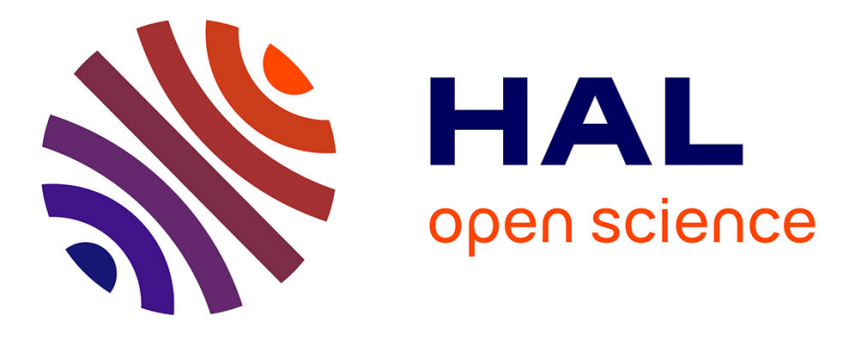

\title{
Synthesis and Photocatalytic Properties of BiOCl Nanowire Arrays
}

Sujaun Wu, Cong Wang, Yinfang Cui, Tianmin Wang, Baibiao Huang, Xiaoyang Zhang, Xiaoyan Qin, Pascal Brault

\section{To cite this version:}

Sujaun Wu, Cong Wang, Yinfang Cui, Tianmin Wang, Baibiao Huang, et al.. Synthesis and Photocatalytic Properties of BiOCl Nanowire Arrays. Materials Letters, 2010, 64, pp.115-118. 10.1016/j.matlet.2009.10.010 . hal-00426784

\section{HAL Id: hal-00426784 https://hal.science/hal-00426784}

Submitted on 27 Oct 2009

HAL is a multi-disciplinary open access archive for the deposit and dissemination of scientific research documents, whether they are published or not. The documents may come from teaching and research institutions in France or abroad, or from public or private research centers.
L'archive ouverte pluridisciplinaire HAL, est destinée au dépôt et à la diffusion de documents scientifiques de niveau recherche, publiés ou non, émanant des établissements d'enseignement et de recherche français ou étrangers, des laboratoires publics ou privés. 
To appear in Materials Letters

\title{
Synthesis and Photocatalytic Properties of BiOCl Nanowire Arrays
}

Sujuan $\mathrm{Wu}^{1}$, Cong Wang ${ }^{1}$, Yinfang $\mathrm{Cu}^{1}$, Tianmin Wang ${ }^{1}$, Baibiao Huang ${ }^{2}$, Xiaoyang Zhang ${ }^{2}$, Xiaoyan Qin ${ }^{2}$, Pascal Brault ${ }^{3}$

1 Center for Condensed Matter and Material Physics, School of Science, Beihang University, Beijing, 100191, China

2 State Kay Laboratory of Crystal Materials, Shandong University, Ji’nan 250100, China

3 GREMI UMR 6606 CNRS-Université d'Orléans, 14, rue d'Issoudun BP 6744, F-45067 ORLEANS

Cedex 2, France

\begin{abstract}
Bismuth oxychloride $(\mathrm{BiOCl})$ nanowire arrays have been successfully prepared employing the Anodic Aluminum Oxide (AAO) template assisted sol-gel method. Nanowires of $100 \mathrm{~nm}$ diameter and length 2- $6 \mu \mathrm{m}$, assembled in the porous of AAO templates, were formed. XRD and HRTEM results show that the nanowires are pure $\mathrm{BiOCl}$ polycrystal phase without $\mathrm{Bi}_{2} \mathrm{O}_{3}$ or $\mathrm{BiCl}_{3}$. The photocatalytic activity of $\mathrm{BiOCl}$ nanowire arrays was investigated by the degradation of Rhodamine B dye solution under UV irradiation.

*Corresponding author. FAX:+86-10-82338346

E-mail address: congwang@buaa.edu.cn (Cong Wang )
\end{abstract}

Key words:

BiOCl, Nanowire arrays, AAO template, Photocatalysis 


\section{Introduction}

During the last few decades low dimensional nanostructured materials have attracted special interest due to their novel properties and potential applications in electronics, photonic devices, and photocatalytic media [1-3]. As these novel properties are highly dependent on shape and size, the size and morphological control of nanostructured materials becomes increasingly important in nanoscience and nanotechnology [4]. In particular, ordered nanostructures are extremely desirable in photocatalytic actions, because their enhance surface-to-volume and substrate-support ratio $[5,6]$.

There has been considerable effort towards the synthesis of ordered structures, the most common being via the nanoporous anodized aluminum oxide (AAO) assisted route. Using easily controlled AAO membranes as a template and combined with electrodepositon deposition, sol-gel deposition, or polymerization, the size and shape of the products can be adjusted [7]. Normally, the pore size of AAO templates can be adjusted from 25 to $300 \mathrm{~nm}$ by changing the anodizing conditions, and the aspect ratio of the AAO membrane can be changed by controlling the anodizing time [8]. Until now, nanotubes, nanowires and nanowire arrays of a variety of inorganic materials have been successfully prepared using this method [9-11].

Bismuth oxychloride (BiOCl), with a bandgap of $3.5 \mathrm{eV}$, has industrial applications as a pigment in cosmetic industry, has been used as a catalyst for the oxidative cracking of hydrocarbons and also as photoluminescent material [12]. Recently, Zhang et al. reported that $\mathrm{BiOCl}$ nanoparticles can be an efficient photocatalyst in decomposing methyl orange under UV light [13]. This indicates that $\mathrm{BiOCl}$ is a potential photocatalyst under UV light irradiation and can compete with $\mathrm{TiO}_{2}$. In 2009, Lee et al. also reported that a 
$\mathrm{BiOCl} / \mathrm{Bi}_{2} \mathrm{O}_{3}$ heterojunction is a new visible light photocatalyst [14]. This harmless and green material has already been synthesized as spherical nanofibers, nanobelts and hierarchical nanoplate microspheres [15-17]. However, to our knowledge, no attempt has been made to fabricate nanowire arrays which will be helpful in photocatalysis reactions [5]. Herein, we exploit the AAO template combined with sol-gel method to prepare $\mathrm{BiOCl}$ nanowire arrays. We characterize the nanostructure and analyze their photocatalytic properties.

\section{Experimental}

$\mathrm{BiOCl}$ powders were first prepared by dissolving $\mathrm{Bi}_{2} \mathrm{O}_{3}$ (AR, Shanghai) in an excessive concentrated $\mathrm{HCl}[16]$. The resulting pure $\mathrm{BiOCl}(2 \mathrm{~g})$ was then dissolved in 20 $\mathrm{ml}$ of ethanol $(95 \% \mathrm{v} / \mathrm{v})$ by adding $5 \mathrm{M} \mathrm{HCl}$ to adjust the $\mathrm{pH}$ value to 1 under constant stirring. Thereafter the resultant solution was stirred at $60{ }^{\circ} \mathrm{C}$ for $3 \mathrm{~h}$ to form sol solution. Subsequently, AAO templates prepared by a two step anodization process were placed in a vessel containing an appropriate amount of $\mathrm{BiOCl}$ sol. The sol was allowed to permeate through the membrane for $30 \mathrm{~min}$ under vacuum conditions, and the sol was crystallized in this process. Finally, the templates assembled with precursor were dried at $100{ }^{\circ} \mathrm{C}$ for $10 \mathrm{~h}$. To remove the templates, the samples were dissolved using $5 \% \mathrm{NaOH}$ and rinsed with distilled water.

The Field Emission Scanning Electron Microscope (FESEM) images and energy-dispersive x-ray spectroscopies (EDS) were recorded on a FEI-SIRION Field Emission Gun-Scanning Electron Microscope. High Resolution Transmission Electron Microscopy (HRTEM) images and Selected-area Electron Diffraction (SAED) patterns 
were obtained on a JEOL 2010 FEG. The phase structure characterization of $\mathrm{BiOCl}$ nanowire arrays was carried out by X-ray Diffraction (XRD) on a Bruker D8 diffractometer with $\mathrm{Cu} \mathrm{K} \alpha$ radiation. The UV-Vis absorption spectra were examined using a Hitachi U-3010 spectrometer.

The photocatalytic activity of the samples was evaluated by the degradation of a Rhodamine B (Rh B) dye solution. Prior to the photocatalytic test, part of the template assembled by $\mathrm{BiOCl}$ nanowires was dissolved. $3 \mathrm{~cm}^{2} \mathrm{BiOCl}$ nanowire arrays were placed in $20 \mathrm{ml} 0.01 \mathrm{mmol} \mathrm{Rh} \mathrm{B}$ solution. This solution was immersed in darkness for $24 \mathrm{~h}$ to reach the adsorption-desorption equilibrium. Then it was irradiated by a $35 \mathrm{~W} \mathrm{Hg}$ lamp with a main emission wavelength of $313 \mathrm{~nm}$. At given intervals of illumination, the samples of the reaction solution were taken out and analyzed using a UV-vis spectrometer (Hitachi U-3010), without centrifugation and filtratation.

\section{Results and discussion}

The morphology and composition of the synthesized products were characterized by FESEM and EDS, respectively. The top view image of the bare AAO template is displayed in Fig.1 (a). The pore size is about $100 \mathrm{~nm}$ and the hexagonal structure is well ordered. From Fig.1 (b), it is observed that $\mathrm{BiOCl}$ nanowire arrays are immersed in the AAO template. The diameter of the nanowires is about $100 \mathrm{~nm}$, which is equal to the pore size of the template used. The pore filling of the AAO template is almost complete. After part of the AAO templates was dissolved, bundles of nanowires were isolated from the templates (Fig.1(c)). The nanowires are nearly parallel to each other and vertically oriented to form an array. The composition of the nanowires was examined using EDS. Fig.1 (d) is one of EDS spectra taken from the cross-section of the nanowires. It indicates 
the presence of $\mathrm{Bi}, \mathrm{Cl}$, and $\mathrm{O}$, and that the $\mathrm{Bi}: \mathrm{Cl}$ atomic ratio is nearly equal to $1: 1$. The $\mathrm{Na}$ peaks in the spectrum come from the $\mathrm{NaOH}$ solution used for dissolving $\mathrm{AAO}$ template.

XRD was employed to identify the crystal structure and phase purity of these nanowire arrays. Fig. 2 shows the XRD pattern of the $\mathrm{BiOCl}$ nanowire arrays in the AAO template. A tetragonal lattice was obtained with $\mathrm{a}=3.89 \AA, \mathrm{c}=7.369 \AA$ and the three strongest peaks are indexed as (101), (110) and (211). Although the background diffraction peaks of $\mathrm{Al}_{2} \mathrm{O}_{3}$ template are present, almost all of the diffraction peaks in the XRD pattern coincide with the standard JCPDS file (No. 85-0861) of BiOCl. There is no other peak corresponding to the peaks of $\mathrm{Bi}_{2} \mathrm{O}_{3}$ or $\mathrm{BiCl}_{3}$. Thus, the synthesized nanowires are crystallized in $\mathrm{BiOCl}$ with high purity. Moreover, the XRD pattern did not change after the photocatalytic reaction, indicating that the synthesized photocatalysts are stable.

HRTEM images were taken in order to observe microstructural details of the BiOCl nanowires. The AAO template was dissolved completely and Fig. 3 (a) shows a TEM image of the isolated nanowires. The average diameter of the nanowires is about $100 \mathrm{~nm}$. The length is only $2 \mu \mathrm{m}$, because it was fractured during the preparation of the TEM samples. We also observed one separated nanowires with the length of $6 \mu \mathrm{m}$ after the template was completely dissolved. The selected area electron diffraction pattern (SAED) (Fig. 3b) shows that the nanowires are polycrystalline, which further confirms the XRD result. The HRTEM (Fig. 3c) also displays a single nanowire that is composed by some small nanocrystals with different orientations.

According to the UV-Visible diffuse reflectance spectra, the band gap of $\mathrm{BiOCl}$ is about $3.4 \mathrm{eV}$. Thus it could be a good candidate as photoelectrode and photocatalytic materials. 
Therefore, the photocatalytic activity of $\mathrm{BiOCl}$ nanowire arrays was evaluated by degradation of Rh B dye under UV light irradiation. Fig. 4(a) shows the absorption spectra of the $\mathrm{Rh} \mathrm{B}$ solution with $\mathrm{BiOCl}$ nanowire arrays in the processes of adsorption in darkness and UV light irradiation for different times. The strong absorption peak of $\mathrm{Rh} \mathrm{B}$ solution located at $554 \mathrm{~nm}$ steadily decreased as the UV irradiation time increased, indicating gradual degradation of the $\mathrm{Rh} \mathrm{B}$ [18]. The initial concentration decreased by $32 \%$ after the dark adsorption and the surface of $\mathrm{BiOCl}$ nanowire arrays turned red. Irradiated under UV light, the red color on both surfaces of $\mathrm{BiOCl}$ nanowire arrays and dye solutions are decreased gradually and could be degraded almost completely after 130 min. Fig. 4(b) shows photodegradation efficiency of Rhodamine B as a function of irradiation time. $\mathrm{C}_{0}$ and $\mathrm{C}$ are the initial and reaction concentrations of aqueous Rhodamine B, respectively. It can be seen that, there is not any degradation of Rh B after adsorption and irriadiation with only bare AAO templates. This indicates that the degradation of $\mathrm{Rh} \mathrm{B}$ is caused by the appearance of $\mathrm{BiOCl}$ nanowires. The photocatalytic reaction can simply be described by $-\mathrm{d}[\mathrm{C}] / \mathrm{dt}=\mathrm{k}[\mathrm{C}]$, where $\mathrm{k}$ is the degradation rate constant, $\mathrm{t}$ is the irradiation time, and [c] is the concentration of $\mathrm{Rh} \mathrm{B}$. In this work, $\mathrm{k}$ was found to be $0.017 \mathrm{~min}^{-1}$. Since the $\mathrm{BiOCl}$ nanowire arrays embed in AAO templates, they can be collected easily without losing any nanowires in the solution. Therefore, they can be recycled for photocatalytic reaction and the efficiency is almost the same. In addition, the large surface-to-volume $(\mathrm{S} / \mathrm{V})$ ratio of nanowire arrays results in an enhanced photocatalytic efficiency $[5,6]$. Both the fixity and the large surface areas in contact with the dye are favorable to the photocatalytic reactions.

\section{Conclusions}


Highly ordered BiOCl nanowire arrays with high photocatalytic efficiency have been successfully prepared via the sol-gel template method. It was found that the nanowires in the arrays were polycrystal, with $100 \mathrm{~nm}$ diameter and $6 \mu \mathrm{m}$ length. $\mathrm{BiOCl}$ nanowire arrays with the band gap of $3.4 \mathrm{eV}$ can efficiently degrade Rh B under UV irridation.

\section{Acknowledgements}

This project was financially supported by the National Basic Research Program of China under grant number 2007CB613302 and National Natural Science Foundation of China (NSFC) ( No. 50772008 )

\section{References}

[1]F. Cesano, S. Bertarione, A. Damin, G. Agostini, S. Usseglio, J. G. Vitillo, C. Lamberti, G. Spoto, D. Scarano, A. Zecchina, Adv. Mater 20 (2008) 3342-3348

[2] Y. Cui, C. M. Lieber, Science 291(2001) 851-853

[3] H. R. Byon, H. C. Choi, J. Am. Chem. Soc. 128 (2006) 2188-2189.

[4] G. Wang, W. Lu, J.H. Li, J. Choi,Y. Jeong, S.Y. Choi, K. Lee, et al., Small 12 (2006) 1436-1439.

[5] H.S. Jung, Y. J. Hong, Y. Li, J. Cho, Y. Kim, G. Yi, ACS Nano. 4 (2008) 637-642.

[6] Y. Lin, Mater. Lett. 62 (2008) 1246-1248.

[7] Q. Wang, X. Sun, S. Luo, L. Sun, X. Wu, M. Cao, and C. Hu, Crystal Growth \& Design. 7 (2007) 2665-2669.

[8] H. Masuda, H. Yamada, M. Satoh, H. Asoh, Appl. Phys. Lett. 71 (1997) 2770-2772.

[9] L. Li, Y. W. Yang, G.H. Li, Li-De Zhang, Small. 2(2006) 548 - 553.

[10] Q.T. Wang, Mater. Lett. 63 (2009) 1493-1495.

[11] X. X. Li, F. Y. Cheng, B. Guo, J. J. Chen, Phys. Chem. B. 109 (2005) 14017-14024.

[12] Z. Deng, F. Tang, A.J. Muscat, Nanotechnology 19 (2008) 295705-1-6 (6pp).

[13] K.L. Zhang, C.M. Liu, F.Q. Huang, C. Zheng, and W. D. Wang, Appl. Catal. B 68 (2006) 
125-129.

[14] S.Y. Chai, Y. J. Kim, M.H. Jung, A.K. Chakraborty, D. Jung, W. I. Lee, J. Catal. 262 (2009) 144-149.

[15] H. Deng, J.W. Wang, Q. Peng, X. Wang, Y.D. Li, Chem. Eur. J. 11 (2005) 6519-6524.

[16] H.Z. An, Y. Du, T.M. Wang, C. Wang, W.C. Hao, J.Y. Zhang, Rare Met. 27 (2008) 243-250.

[17] C.H. Wang, C.L. Shao, Y.C. Liu, and L.N. Zhang, Scripta Mater. 59 (2008) 332-335.

[18] C. Chen, W. Zhao, P. Lei, J. Zhao, N. Serpone, Chem. Eur. J. 10 (2004) 1956-1965.

\section{Figure captions:}

Fig.1 FESEM images: (a) bare AAO template; (b) top view of $\mathrm{BiOCl}$ nanowire arrays; (c) cross-section of BiOCl nanowires after part of the template was dissolved; (d) EDS spectrum of the nanowires.

Fig. 2 XRD pattern of $\mathrm{BiOCl}$ nanowire arrays.

Fig. 3 (a) TEM image of BiOCl nanowires; (b) SEAD pattern of the BiOCl nanowires; (c) HRTEM image of $\mathrm{BiOCl}$ nanowire.

Fig. 4 Absorption spectra of the RhB solutions with $\mathrm{BiOCl}$ nanowire arrays at different stages. 

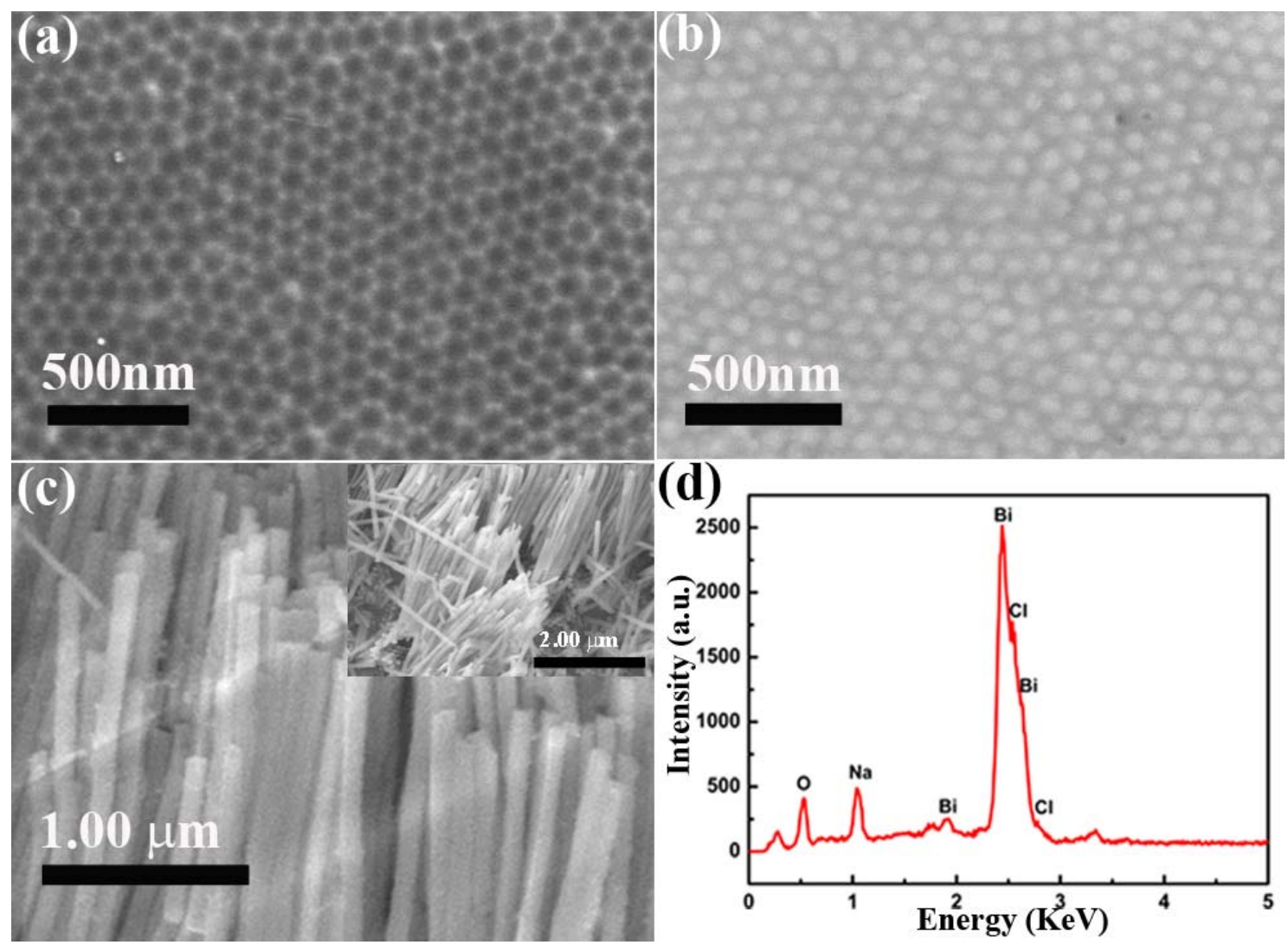

Fig.1 


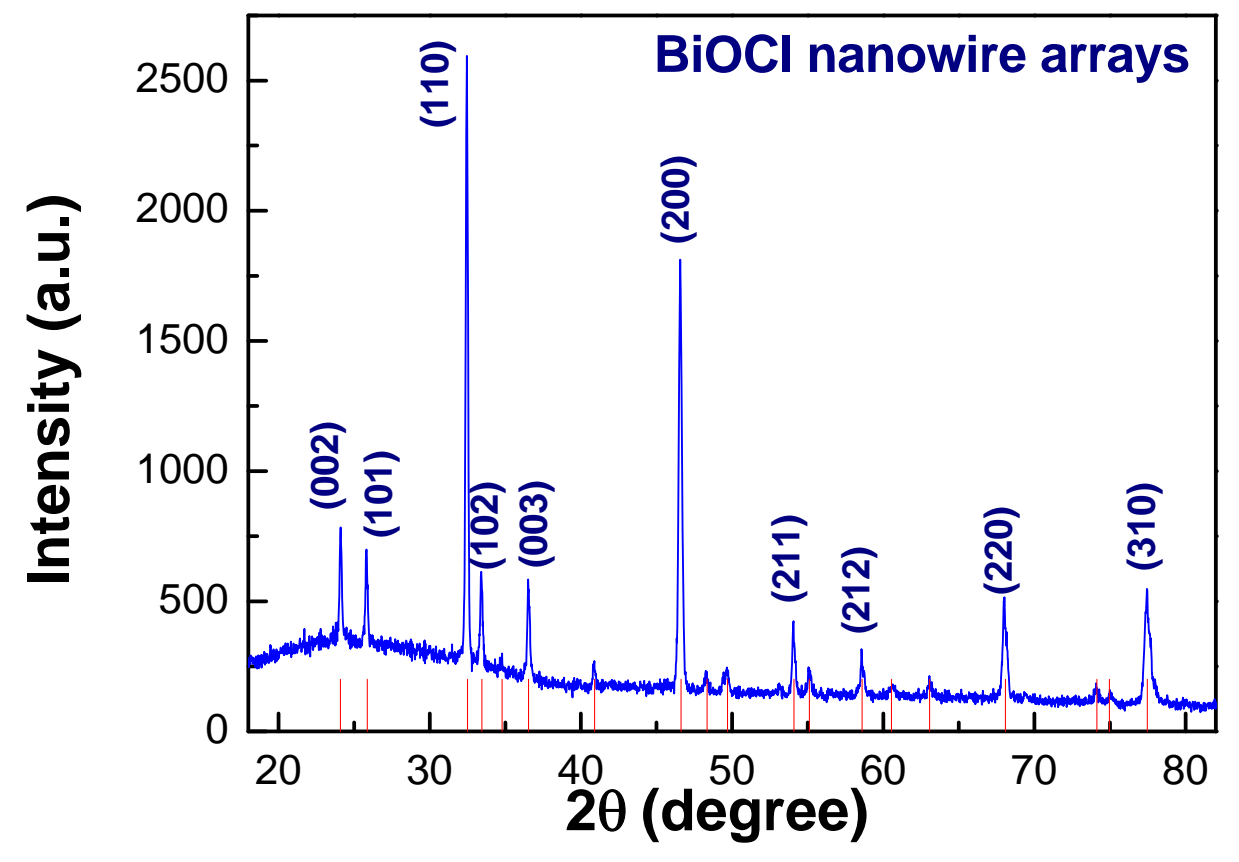

Fig.2 


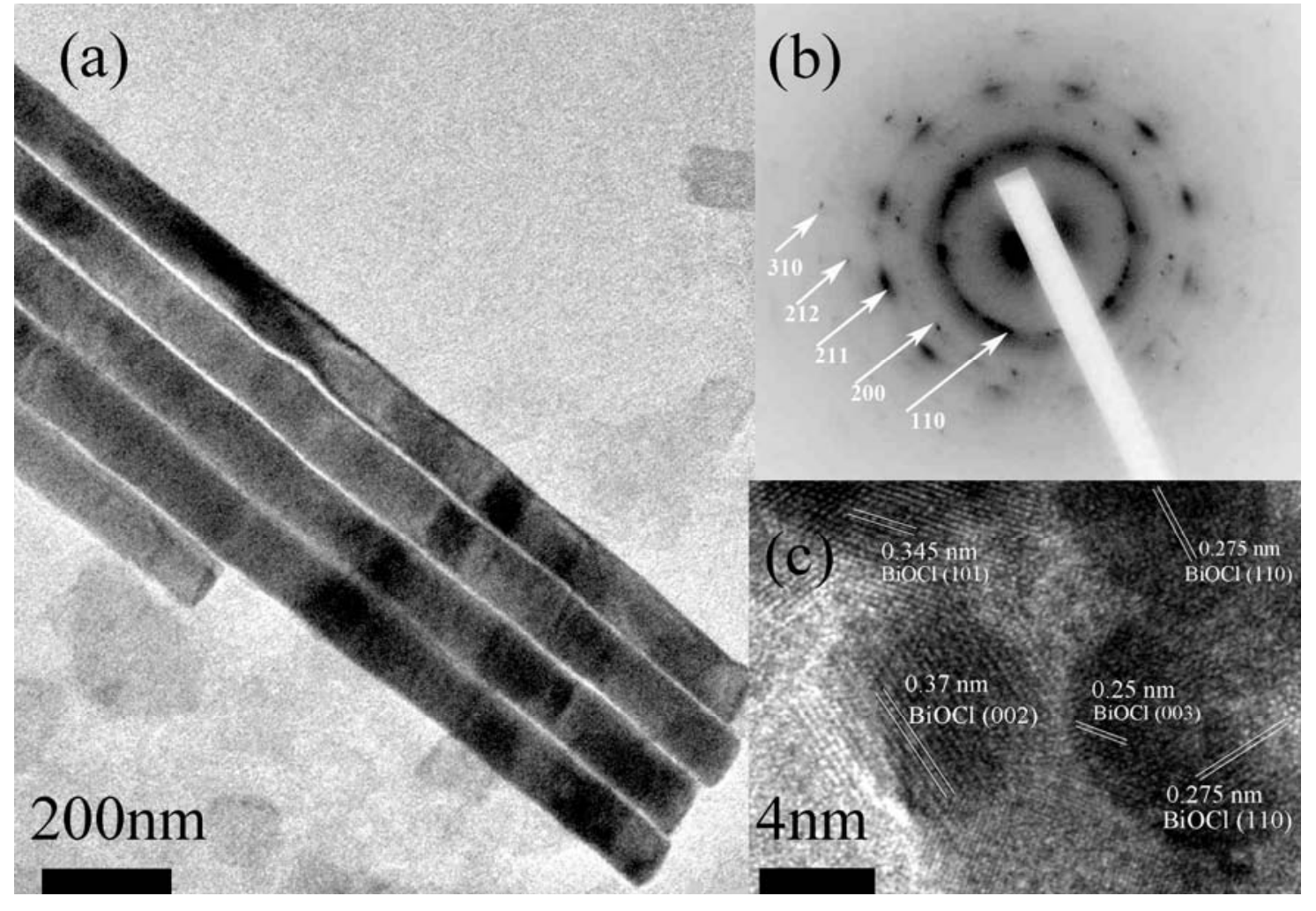

Fig.3 

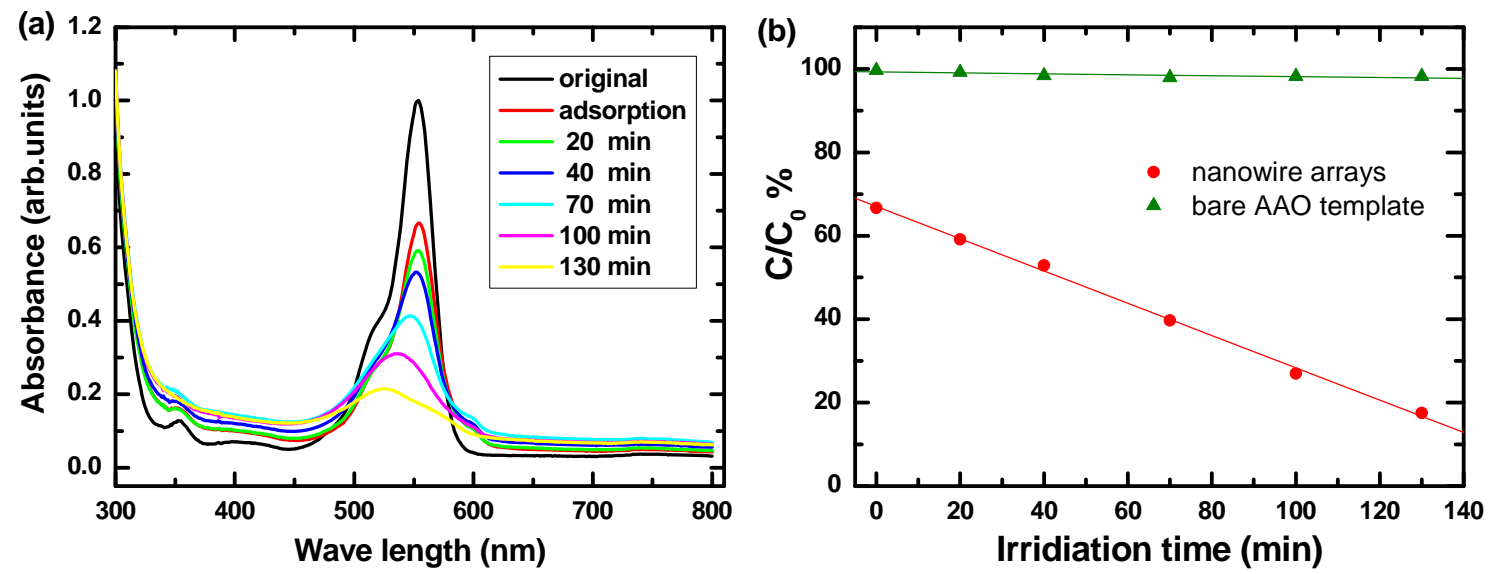

Fig.4 